\title{
Osteoporoz Risk Faktörlerinin Kemik Mineral Yoğunluğuyla Iilişkisi
}

\author{
The Relationship Between Osteoporotic Risk Factors and Bone Mineral Density
}

Şule Şahin Onat, Sibel Ünsal Delialioğlu, Sumru Özel

Ankara Fizik Tedavi Eğitim ve Araştırma Hastanesi, Ankara, Türkiye

\section{Özet}

Amaç: Osteoporozun, bir dereceye kadar önlenebilir bir hastalık olması nedeniyle risk faktörlerinin belirlenmesi ve mümkünse modifiye edilmesi önemlidir. Bu çalışmanın amacı osteoporoz risk faktörleri ile kemik mineral dansite sonuçları arasındaki ilişkinin incelenmesi ve osteoporoz risk faktörlerinin öneminin vurgulanmasıdır.

Gereç ve Yöntem: Çalışmaya 103 postmenopozal osteoporotik hasta dahil edildi. Hastaların demografik özellikleri, osteoporotik risk faktörleri, lumbar vertebra ve femur boyun T skorları kaydedildi. Lumbar vertebra ve femur boyun T skorları ile risk faktörleri arasındaki ilişki istatistiksel olarak incelendi.

Bulgular: Postmenopozal osteoporotik kadınlarda ileri yaş, düşük fiziksel aktivite düzeyi, yetersiz günlük kalsiyum alımı ve vertebral kompresyon fraktürü varlığı düşük kemik mineral dansite sonuçlarıyla ilişkili bulunurken, medeni durum, meslek, eğitim durumu ve ailede kırık öyküsünün varlığı kemik mineral dansite sonuçlarıyla ilişkili bulunmadı. Ayrıca erken menopoz düşük femoral T skorları ile, sigara kullanımı ise düşük lumbar T skorları ile ilişkili bulundu. Düşme eğilimi ve kronik hastalık sayısı ise kemik mineral dansite sonuçlarıyla ilişkisiz bulundu. Sonuç: Osteoporozdan korunmada risk faktörlerinin değerlendirilmesi önemlidir. (Türk Osteoporoz Dergisi 2013;19:74-80)

Anahtar kelimeler: Postmenapozal osteoporoz, risk faktörü, kemik mineral yoğunluğu

\section{Summary}

Objective: Since osteoporosis is a preventable disease to some extent, risk factor determination and if possible modification is very important. The aim of this study is to identify the relationship between ostoporotic risk factors and bone mineral density results and emphasize the importance of risk factors.

Materials and Methods: The study comprised 103 postmenopausal osteoporotic women. Demographic characteristics, osteoporortic risk factors, lumbar vertebrae and femur neck T scores were recorded. Relationships between lumbar vertebra and femur neck T scores and risk factors were statistically studied.

Results: Advanced age, low physical activity status, inadequte dietary calcium intake and vertebral compression fractures were found to be associated with low bone mineral density results in postmenopausal osteoporotic women whereas marital status, occupation, education level and familial fracture history were not. Furthermore early menopause was found to be associated with low femoral T scores and smoking with low lumbar T scores. Tendency to fall and number of chronic diseases were irrelevant to bone mineral density.

Conclusions: Risk factor assesment is still important for osteoporosis prevention. (Turkish Journal of Osteoporosis 2013;19:74-80)

Key words: Postmenopausal osteoporosis, risk factors, bone mineral density

Yazışma Adresi/Address for Correspondence: Dr. Şule Şahin Onat, Ankara Fizik Tedavi Eğitim ve Araştırma Hastanesi, Ankara, Türkiye GSM: +90 5053136848 E-posta: sahinsulester@gmail.com Geliş Tarihi/Received: 05.07.2013 Kabul Tarihi/Accepted: 24.10.2013

Türk Osteoporoz Dergisi, Galenos Yayınevi tarafından basılmıștır. / Turkish Journal of Osteoporosis, published by Galenos Publishing. 


\section{Giriş}

Osteoporoz (OP) sessiz bir hastalık olduğu için tanı konulduğunda tedavisi daha zor olmaktadır ve bu yüzden koruyucu hekimliğin en ön planda uygulanması gereken hastalıklardan biridir. Tabi bu durumda OP için belirlenmiş olan risk faktörlerinin belirlenmesinin önemi daha da artmaktadır. Dünya Sağlık Örgütü (DSÖ) Metabolik Kemik Hastalıkları için Işbirliği Merkezi tarafından bireylerin kırık riskini değerlendirmek için FRAX® (The World Health Organization Fracture Risk Assessment Tool) diye bir araç geliştirilmiştir (1). Bu modelde yaş, cinsiyet, vücut ağılığı, önceki geçirilmiş frajilite kırığı, annede kırık hikayesinin varlığı, sigara içimi, uzun süreli glukokortikoid kullanımı, romatoid artrit, diğer sekonder osteoporoz nedenleri ve aşırı alkol tüketimi bireylerin mutlak kırık riskini belirlemede kullanılan faktörler olarak belirlenmiştir (1). FRAX modelinde bazı önemli kırık risk faktörlerinin mevcut olmaması (kırılganlık, düşmeler ve kemik döngüsü gibi), "Evet" ve "Hayır" olarak cevaplanan risk faktörleri için doz etkisinin göz önüne alınmamış olması, kemik mineral yoğunluğu (KMY) girişinin "femur boynu" KMY ile sınırlı olması, fraktür riskinin olduğundan daha fazla veya daha az tahmin edilebilir olması ve tedavi edilmiş hastalarda kullanılamıyor olması gibi dezavantajları bulunmaktadır (2). Bundan dolayı çalışmamızda risk faktörleri olarak yaş, medeni durum, eğitim düzeyi, mesleki özellikler, vücut ağırlığı, menapoz yaşı, 50 yaşın altında hastada ve/veya annede frajilite kırı̆ı öyküsünün olması, diyetle kalsiyum, kahve ve alkol tüketimi, sigara kullanımı, eşlik eden kronik hastalık varlığı, osteoporoz neden olabilecek ilaç kullanımı, fiziksel aktivite düzeyi, düşmeye yatkınlık, vertebral kompresyon kırığı sorgulandı. Peki risk faktörleriyle KMY arasında nasıl bir ilişki bulunmaktadır? Kemik mineral yoğunluğu ölçüm yapılan alandaki kemik mineral dansitesi olup kemiğin fizyolojik ve patolojik durumunun önemli bir göstergesidir (3). KMY ölçümü OP tanısı ve kemikte kırık oluşma riskinin saptanması açısından önemlidir. KMY değerlerinin ırksal, genetik, cinsiyet, yaş, çevresel ve bölgesel faktörlerden etkilendiği bilinmektedir $(3,4)$. OP'daki risk faktörleri ile KMY'nun ilişkisini değerlendiren çalışmalar kronik böbrek hastalığı gibi spesifik hastalık gruplarında odaklanmıştır (5). Bundan dolayı biz de çalışmamızda risk faktörleriyle KMY ilişkisini ortaya koyup risk faktörlerinin önemini vurgulamayı hedefledik.

\section{Gereç ve Yöntem}

Kesitsel tipteki bu çalışmanın örneklemini fizik tedavi ve rehabilitasyon polikliniğine başvuran DSÖ kriterlerine göre Dual Foton X-Ray Absorbsiometry (DXA) ile osteoporoz tanısı konulmuş 103 postmenapozal kadın hasta oluşturmaktadır. Hastalar başvurularına göre ardı sıra alındı. Osteoporoz tedavisi (bifosfonat, kalsitonin, D vitamini, kalsiyum, vb.) alan olgular çalışma dışı bırakıldı. Hastane lokal etik kurulundan onayı alındı. Hastalar çalışma ile ilgili bilgilendirilerek hasta onamları alındı. Hastalara yaş, medeni durum, eğitim düzeyi, meslek, boy, kilo, menapoz yaşı, diyetle günlük kalsiyum alımı, günlük kahve tüketimi, alkol kullanımı (içmiyor\sosyal içici\sürekli içici), sigara kullanımı (paket\gün\yıl), fiziksel aktivite düzeyi (düzenli egzersiz yapıyor (ara sıra egzersiz yapıyor \hiç egzersiz yapmıyor), ailede kırık hikayesi, frajilite kırığı hikayesi, eşlik eden kronik hastalık varlığı ve osteoporoz neden olabilecek ilaç kullanımını içeren sorgulama formu dolduruldu.

Menopoz yaşının 45'in altında olması, 50 yaşın altında hastada ve/veya annede frajilite kırığı öyküsünün olması OP için risk faktörü olarak kabul edildi (6).

Hastaların diyet özelliklerinden günlük süt ve eşdeğer besinlerin (bir bardak süt=bir kibrit kutusu kadar peynir=1 kase yoğurt) tüketimi sorgulandı ve hiç birini almaması OP için risk faktörü olarak değerlendirildi (7). Yine diyette günlük 1 fincandan fazla kahve (150 mg) alımı, günde 2 bardaktan fazla alkolün düzenli kullanımı ve düzenli sigara içimi risk faktörü olarak kabul edildi (7).

Fiziksel aktivite düzeyinin değerlendirilmesinde, sadece günlük yaşam aktivitelerini içeren aktiviteleri yapan ve 30 dakikadan daha az yürüyüş yapanlar 'düşük fiziksel aktivite düzeyi', 30 dakikadan fazla günlük yürüyüş yapanlar 'ara sıra egzersiz yapıyor' ve düzenli egzersiz uygulayanlar ise 'düzenli egzersiz yapıyor' olarak gruplandırıldı. Düşük fiziksel aktivite düzeyi risk faktörü olarak kabul edildi (7).

Hastaların boy ve kilo ölçümlerinden vücut kitle indeksi (VKi) (kilo/(boy) $)^{2}$ kg/m² cinsinden hesaplandı. Vücut yapısının VKi'nin $\leq 18,5$ zayıf, 18,5-24,9 ideal kilolu, 25-29,9 fazla kilolu, VKi $\geq 30$ obez olarak gruplandırıldı (8). VKi'nin zayıf olması osteoporoz için risk faktörü olarak kabul edildi (6).

Hastaların düşmeye yatkınlıkları düşme açısından risk faktörlerinin sorgulanmasıyla değerlendirildi (7). Görme bozukluğu, yürüme bozukluğu, yardımcı cihaz kullanımı, hipoglisemi atakları, postural hipotansiyon, düşmeye neden olabilecek ek hastalıkların varlığı (serebrovasküler olay, Parkinson hastalığı, katarakt, Meniere hastalığı, kardiak aritmi), yaşadıkları ortam (merdiven olması, kötü aydınlatma, bahçe ve ev çevresinde engebelerin varlığı) sorgulanarak değerlendirildi (7).

Olguların iki yönlü torakal ve lomber vertebra grafileri çekilerek tüm vertebralarda ön, orta, arka yükseklikler ölçüldü ve vertebral kompresyon kırı̆̆ı (VKK) geçirip geçirmediği kaydedildi (9). Vertebral kompresyon kırığı olması OP için risk faktörü olarak kabul edildi (6).

Osteoporoz tanısı klinik değerlendirme, lateral vertebral grafiler (torasik ve lomber), lomber L1-L4 ve femur KMY değerleri doğrultusunda konuldu. Hastaların kemik mineral yoğunluğu ölçümü lomber vertebralardan (L1-L4 arası anterior pozisyonda) ve proksimal femurdan DXA cihazı (LUNAR DPX-IQ) ile değerlendirildi. Kemik mineral yoğunluğu değerlerine göre $T$ skoru genç yetişkin ortalamasına göre $-2,5$ SD'nin altında olanlar (T skor>-2,5) osteoporotik olarak değerlendirilmiştir. Varyasyon katsayısı lomber omurda \%0,7 ve kalçada \%1'dir (10). KMY sonuçları alan yoğunluğu (g/ $\mathrm{cm}^{2}$ ) olarak verilmiştir.

\section{İstatistiksel Analiz}

Verilerin analizi SPSS for Windows 20.0 paket programında yapıldı. Tanımlayıcı istatistikler sürekli değişkenler için ortalama sstandart sapma biçiminde, nominal değişkenler için ise 
gözlem sayısı ve (\%) şeklinde gösterildi. Medeni durum, meslek, eğitim durumu, erken menapoz hikayesi, sigara kullanımı, ailede kırık hikayesi, vertebral kompresyon kırığı gruplarının ortalamasının karşılaştırılmasında independent t testi kullanıldı. Veriler normal dağılıma uyduğu için parametrik test yapıldı. Üç gruptan oluşan yaş, fiziksel aktivite düzeyi, vücut kitle indeksi, kronik hastalık sayısının grup ortalamalarının karşılaştırımasında oneway ANOVA testi kullanıldı. Gruplar arasındaki farklılığın hangisinden kaynaklandığını bulmak için posthoc analiz yapıldı. $p<0,05$ için sonuçlar istatistiksel olarak anlamlı kabul edildi.

\section{Bulgular}

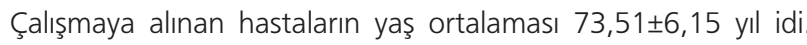
Hastalar yaşlarına göre 55-65 yaş arası, 65-75 yaş arası ve 75-85 yaş arası olmak üzere üç gruba ayrıldı. Hastalarda osteoporoz risk faktörlerinin dağılımı ilgili tabloda özetlenmiştir (Tablo 1). Hastalar yaş gruplarına göre değerlendirildiğinde üç grubun arasında lomber $T[f(2,100)=10,36 p<0,001]$ ve femur $T$ $[f(2,100)=9,36 p<0,0001]$ değerleri açısından istatistiksel olarak anlamlı farklılık bulundu. Lomber T skorlarındaki farklıığın hangi gruptan kaynaklandığını anlamak için posthoc test yapıldığında 55-65 yaş arası grup ortalamasıyla $(-2,93 \pm 0,34)$ 65-75 yaş arası grup ortalaması $(-3,14 \pm 0,41)$ arasında istatistiksel olarak anlamlı farklılık saptanmadı $(p=0,395)$. 55-65 yaş arası yapan grubun ortalamasılyla $(-2,93 \pm 0,34) 75-85$ yaş arası grubun ortalaması $(-3,55 \pm 0,64)$ arasında istatistiksel olarak anlamlı farklılık saptandı $(p=0,001)$. 65-75 yaş arası grup ortalamasıyla $(-3,14 \pm 0,41) 75-85$ yaş arası grup ortalaması $(-3,55 \pm 0,64)$ arasında istatistiksel olarak anlamlı farklılık saptandı $(p=0,001)$. Femur T skorlarındaki farklıığın hangi gruptan kaynaklandığını anlamak için posthoc test yapıldığında 55-65 yaş arası grup ortalamasıyla $(-2,19 \pm 0,48) 65-75$ yaş arası grup ortalaması $(2,19 \pm 0,66)$ arasında istatistiksel olarak anlamlı farklıık saptandı $(p=0,001)$. 55-65 yaş arası yapan grubun ortalamasıyla $(-2,19 \pm 0,48) 75-85$ yaş arası grubun ortalaması $(-2,73 \pm 0,63)$ arasında istatistiksel olarak anlamlı farklılı saptandı $(p=0,020)$. 65-75 yaş arası grup ortalamasıyla $(-2,19 \pm 0,66)$ 75-85 yaş arası grup ortalaması $(-2,73 \pm 0,63)$ arasında istatistiksel olarak anlamlı farklılık saptandı $(p=0,001)$.

Medeni durum, meslek, eğitim durumu, erken menapoz hikayesi, sigara kullanımı, ailede kırık hikayesi, düşme eğilimi, vertebral kompresyon kırığı olan grupların KMY ortalamalarının karşılaştırıldığı test sonuçları ilgili tabloda özetlenmiştir (Tablo 2). Buna göre medeni durum, meslek, eğitim durumu ve ailede kırık hikayesinin olmasının KMY'nu etkilemediği, erken menapoz hikayesi olmasının düşük femur KMY değerleriyle, sigara kullanımının düşük lomber KMY değerleriyle ilişkili olduğu görüldü. Diyette yetersiz kalsiyum alımı ve vertebral kompresyon kırığının ise hem lomber hem de femurda düşük KMY değerleriyle ilişkili olduğu görülmüştür. Düşmeye eğilimi olan ve olmayan grupların KMY ortalamaları arasında farklılık gözlenmedi. Hastalarımızın hiçbirinde fazla kahve ve alkol tüketimi bulunmamaktaydı.
Tablo 1. Postmenapozal osteoporotik kadın hastalarımızda osteoporoz risk faktörlerinin dağılımı

\begin{tabular}{|c|c|}
\hline Risk faktörü & n (\%) \\
\hline \multicolumn{2}{|l|}{ Yaş } \\
\hline 55-65 yaş arası & $13(12,6)$ \\
\hline $65-75$ yaş arası & $45(43,7)$ \\
\hline $75-85$ yaş arası & $45(43,7)$ \\
\hline \multicolumn{2}{|l|}{ Medeni durum } \\
\hline Evli & $70(68)$ \\
\hline Evli değil & $33(32)$ \\
\hline \multicolumn{2}{|l|}{ Meslek } \\
\hline Aktif çalışmayan & $97(94,2)$ \\
\hline Aktif çalışan & $6(5,8)$ \\
\hline \multicolumn{2}{|l|}{ Eğitim durumu } \\
\hline Okuryazar & $51(49,5)$ \\
\hline Okuryazar değil & $52(50,5)$ \\
\hline \multicolumn{2}{|l|}{ Erken menapoz } \\
\hline Var & $21(20,4)$ \\
\hline Yok & $82(79,6)$ \\
\hline \multicolumn{2}{|l|}{ Sigara kullanımı } \\
\hline Var & $19(18,4)$ \\
\hline Yok & $84(81,6)$ \\
\hline \multicolumn{2}{|l|}{ Fiziksel aktivite düzeyi } \\
\hline Düzenli egzersiz yapan & $25(24,3)$ \\
\hline Ara sıra egzersiz yapan & $29(28,2)$ \\
\hline Hiç egzersiz yapmayan & $49(47,5)$ \\
\hline \multicolumn{2}{|l|}{ Vücut kitle indexi } \\
\hline İdeal kilolu & $17(16,5)$ \\
\hline Fazla kilolu & $35(34)$ \\
\hline Obez & $51(49,5)$ \\
\hline \multicolumn{2}{|l|}{ Diette yetersiz kalsiyum alımı } \\
\hline Var & $76(73,8)$ \\
\hline Yok & $27(26,2)$ \\
\hline \multicolumn{2}{|l|}{ Ailede kırık hikayesi } \\
\hline Var & $15(14,6)$ \\
\hline Yok & $88(85,4)$ \\
\hline \multicolumn{2}{|l|}{ Frajilite kırığı hikayesi } \\
\hline Var & $3(2,9)$ \\
\hline Yok & $100(97,1)$ \\
\hline \multicolumn{2}{|l|}{ Düşme eğilimi } \\
\hline Var & $12(11,7)$ \\
\hline Yok & $91(88,3)$ \\
\hline \multicolumn{2}{|l|}{ Vertebral kompresyon kırığı } \\
\hline Var & $33(32)$ \\
\hline Yok & $70(68)$ \\
\hline \multicolumn{2}{|l|}{ Komorbidite durumu } \\
\hline Kronik hastalığı olmayan & $22(21,4)$ \\
\hline Bir kronik hastalığı olan & $49(47,6)$ \\
\hline iki ve daha fazla kronik hastalığı olan & $32(31,1)$ \\
\hline \multicolumn{2}{|l|}{ Osteoporoza neden olan ilaç kullanımı } \\
\hline Var & $5(4,9)$ \\
\hline Yok & $98(95,1)$ \\
\hline
\end{tabular}


Tablo 2. Postmenapozal osteoporotik kadın hastaların
osteoporoz risk faktörlerine göre femur ve lomber KMY değerlerinin karșılaștırıması

\begin{tabular}{|c|c|c|}
\hline & $\begin{array}{c}\text { Lomber KMY } \\
\text { ortalaması } \\
\left(\mathrm{gr} \mid \mathrm{cm}^{2}\right)\end{array}$ & $\begin{array}{c}\text { Femur KMY } \\
\text { ortalaması } \\
\left(\mathrm{gr} \backslash \mathrm{cm}^{2}\right)\end{array}$ \\
\hline \multicolumn{3}{|l|}{ Medeni durum } \\
\hline Evli & $-3,20 \pm 0,52$ & $-2,34 \pm 0,66$ \\
\hline Evli değil & $-3,28 \pm 0,62$ & $-2,61 \pm 0,68$ \\
\hline $\mathbf{p}$ & 0,059 & 0,057 \\
\hline \multicolumn{3}{|l|}{ Meslek } \\
\hline Aktif çalışan & $-3,38 \pm 0,34$ & $-2,26 \pm 0,70$ \\
\hline Aktif çalısmayan & $-3,29 \pm 0,58$ & $-2,44 \pm 0,68$ \\
\hline $\mathbf{p}$ & 0,705 & 0,543 \\
\hline \multicolumn{3}{|l|}{ Eğitim durumu } \\
\hline Okuryazar & $-3,24 \pm 0,52$ & $-2,30 \pm 0,66$ \\
\hline Okuryazar değil & $-3,35 \pm 0,61$ & $-2,55 \pm 0,68$ \\
\hline$p$ & 0,345 & 0,058 \\
\hline \multicolumn{3}{|c|}{ Erken menapoz hikayesi } \\
\hline Olan & $-3,35 \pm 0,70$ & $-2,70 \pm 0,67$ \\
\hline Olmayan & $-3,28 \pm 0,53$ & $-2,36 \pm 0,66$ \\
\hline $\mathbf{p}$ & 0,592 & $0,039^{*}$ \\
\hline \multicolumn{3}{|l|}{ Sigara kullanımı } \\
\hline Olan & $-2,82 \pm 0,45$ & $-2,30 \pm 0,58$ \\
\hline Olamayan & $-3,40 \pm 0,54$ & $-2,46 \pm 0,70$ \\
\hline $\mathbf{p}$ & $0,0001^{*}$ & 0,372 \\
\hline \multicolumn{3}{|c|}{$\begin{array}{l}\text { Diette yetersiz kalsiyum } \\
\text { alımı }\end{array}$} \\
\hline Olan & $-3,37 \pm 0,58$ & $-2,49 \pm 0,63$ \\
\hline Olmayan & $-3,02 \pm 0,40$ & $-2,29 \pm 0,80$ \\
\hline $\mathbf{p}$ & $0,010^{*}$ & $0,007^{\star}$ \\
\hline \multicolumn{3}{|c|}{ Ailede kırık hikayesi } \\
\hline Olan & $-3,27 \pm 0,43$ & $-2,32 \pm 0,75$ \\
\hline Olmayan & $-3,30 \pm 0,59$ & $-2,45 \pm 0,67$ \\
\hline $\mathbf{p}$ & 0,863 & 0,494 \\
\hline \multicolumn{3}{|l|}{ Düşme eğilimi } \\
\hline Olan & $-3,46 \pm 0,73$ & $-2,71 \pm 0,64$ \\
\hline Olmayan & $-3,27 \pm 0,54$ & $-2,39 \pm 0,68$ \\
\hline $\mathbf{p}$ & 0,276 & 0,124 \\
\hline \multicolumn{3}{|c|}{$\begin{array}{l}\text { Vertebral kompresyon } \\
\text { kırığı }\end{array}$} \\
\hline Olan & $-3,56 \pm 0,62$ & $-2,63 \pm 0,71$ \\
\hline Olmayan & $-3,17 \pm 0,49$ & $-2,33 \pm 0,64$ \\
\hline$p$ & 0,001 * & $0,036^{*}$ \\
\hline
\end{tabular}

Fiziksel aktivite düzeyine göre (düzenli egzersiz yapma, ara sıra egzersiz yapma, hiç egzersiz yapmama) gruplar arasında lomber $T[f(2,100)=35,42 p<0,001]$ ve femur $T[f(2,100)=4,66$ $p=0,012]$ değerleri açısından istatistiksel olarak anlamlı farklılık bulundu. Lomber T skorlarındaki farklılı̆ın hangi gruptan kaynaklandığını anlamak için posthoc test yapıldığında düzenli egzersiz yapan grup ortalamasıyla $(-2,71 \pm 0,23)$ ara sıra egzersiz yapan grup ortalaması $(-3,25 \pm 0,40)$ arasında istatistiksel olarak anlamlı farklılık saptandı $(p=0,001)$. Düzenli egzersiz yapan grubun ortalamasıyla $(-2,71 \pm 0,23)$ hiç egzersiz yapmayan grubun ortalaması $(-3,62 \pm 0,53)$ arasında istatistiksel olarak anlamlı farklıık saptandı $(p=0,001)$. Ara sıra egzersiz yapan grup ortalamasıly $(-3,25 \pm 0,40)$ hiç egzersiz yapmayan grup ortalaması $(-3,62 \pm 0,53)$ arasında istatistiksel olarak anlamlı farklılık saptandı $(p=0,002)$. Femur $T$ skorlarındaki farklılığın hangi gruptan kaynaklandığını anlamak için posthoc test yapıldığında düzenli egzersiz yapan grupla $(-2,08 \pm 0,51)$ ara sıra egzersiz yapan grup $(-2,59 \pm 0,67)$ arasında istatistiksel olarak anlamlı farklılık saptandı $(p=0,015)$. Düzenli egzersiz yapan grubun ortalamasıly $(-2,08 \pm 0,51)$ hiç egzersiz yapmayan grubun ortalaması $(-2,51 \pm 0,71)$ arasında istatistiksel olarak anlamlı farklılık saptandı $(p=0,028)$. Ara sıra egzersiz yapan grup ortalamasıyla $(-2,59 \pm 0,67)$ hiç egzersiz yapmayan grup ortalaması $(-2,51 \pm 0,71)$ arasında istatistiksel olarak anlamlı farklılık saptanmadı $(p=0,842)$.

Vücut kitle indeksine göre (ideal, fazla kilolu, obez) gruplar arasında lomber $T[f(2,100)=21,36 p<0,001]$ ve femur $T$ $[f(2,100)=4,52 p=0,013]$ değerleri açısından istatistiksel olarak anlamlı farklılık bulundu. Lomber $T$ skorlarındaki farklıı̆ın hangi gruptan kaynaklandığını anlamak için posthoc test yapıldığında ideal kilolu grubun ortalamasıyla $(-3,88 \pm 0,70)$ fazla kilolu grubun ortalaması $(-3,40 \pm 0,50)$ arasında istatistiksel olarak anlamlı farklılık saptandı $(p=0,003)$. ideal kilolu grubun ortalamasıyla $(-3,88 \pm 0,70)$ obez grubun ortalaması $(-3,02 \pm 0,36)$ arasında istatistiksel olarak anlamlı farklılık saptandı $(p=0,001)$. Obez grubun ortalamasıyla $(-3,02 \pm 0,36)$ fazla kilolu grubun ortalaması $(-3,40 \pm 0,50)$ arasında istatistiksel olarak anlamlı farklılık saptandı $(p=0,002)$. Femur $T$ skorlarındaki farklılığın hangi gruptan kaynaklandığını anlamak için posthoc test yapıldığında ideal kilolu grubun ortalamasıyla $(-2,74 \pm 0,69)$ fazla kilolu grubun ortalaması $(-2,55 \pm 0,64)$ arasında istatistiksel olarak anlamlı farklılık saptanmadı $(p=0,604)$. ideal kilolu grubun ortalamasıyla $(-2,74 \pm 0,69)$ obez grubun ortalaması $(2,24 \pm 0,65)$ arasında istatistiksel olarak anlamlı farklılık saptandı $(p=0,023)$. Obez grubun ortalamasiyla $(-2,24 \pm 0,65)$ fazla kilolu grubun ortalaması $(-2,55 \pm 0,64)$ arasında istatistiksel olarak anlamlı farklılık saptanmadı $(p=0,088)$.

Hastaların komorbid durumları kronik hastalığı olmayan, bir kronik hastalığı olan, iki ve daha fazla kronik hastalığı olan şeklinde gruplandırıldı. Bu üç grubun lomber $T$ değerleri karşılaştırıldığında kronik hastalığı olmayan grubun ortalaması $(-3,21 \pm 0,57)$, bir kronik hastalığı olan grubun ortalaması $(-3,24 \pm 0,53)$, iki ve daha fazla kronik hastalığı olan grubun ortalaması $(-3,43 \pm 0,61)$ arasında istatistiksel olarak anlamlı 
farklılık saptanmadı [lomber $f(2,100)=1,31 p=0,273]$. Hastaların kronik hastalık sayılarına göre femur T değerleri karşılaştırıldığında kronik hastalığı olmayan grubun ortalaması $(-2,36 \pm 0,66)$, bir kronik hastalığı olan grubun ortalaması $(-2,37 \pm 0,73)$, iki ve daha fazla kronik hastalığı olan grubun ortalaması $(-2,56 \pm 0,60)$ arasında istatistiksel olarak anlamlı farklılık saptanmadı [femur $f(2,100)=0,851 p=0,430]$.

Fragilite kırı̆ı̆ı hikayesi olan hastaların lomber T değeri ortalaması $-3,76 \pm 1,05$, olmayan hastaların lomber $T$ değeri ortalaması $-3,28 \pm 0,55$ idi. Fragilite kırığı hikayesi olan hastaların femur $\mathrm{T}$ değeri ortalaması $-3,10 \pm 1,17$, olmayan hastaların femur $\mathrm{T}$ değeri ortalaması $-2,41 \pm 0,66$ idi.

Osteoporoza neden olan ilaç kullanımı olan hastaların lomber T değeri ortalaması $-3,30 \pm 0,58$, olmayan hastaların lomber $T$ değeri ortalaması $-3,20 \pm 0,25$ idi. Osteoporoza neden olan ilaç kullanımı olan hastaların femur T değeri ortalaması $-2,44 \pm 0,67$,

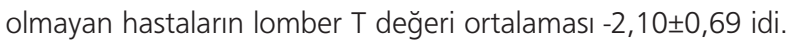

\section{Tartışma}

Kemik mineral yoğunluğunu belirleyen iki ana faktör erişkin yaşa kadar oluşumu devam eden doruk kemik kitlesi ve yaşlııkta hızlanan kemik kaybı gelişimidir $(11,12)$. Lunar DXA ile yapılan bir çok çalışmada kadınlarda KMY'nun yaşla negatif korelasyonu bildirilmiştir (12-15). Türkiye'deki OP sıklığını ve kalça kırı̆̆ı riskini belirlemek amacıyla 12 farklı bölgede, 26,424 katııımc ile görüşme ve Lunar DXA ile KMY taraması şeklinde yapılan FRACTURK çalışmasında, femur boynu osteoporoz sıklığ ülkemizde 50 yaş ve üzeri kadınlarında \%12,9 iken 80 yaş ve üzerinde ise \%37,7 olarak saptanmış ve yaş-cinsiyetle ilişkili osteoporotik kalça kırığı riskinde artış olduğu ifade edilmiştir (16). Çalışmamızda da ileri yaşın düşük KMY için bir risk faktörü olduğu gösterildi. Çünkü ilerleyen yaşla birlikte bağırsaklardan kalsiyum ve D vitamini emilimi, böbreklerden aktif D vitamini oluşumu azalmaktadır. Kalsiyum seviyesinin azalması paratiroid hormon seviyesini arttırmakta, böylece kemik rezorpsiyonu artmakta ve KMY azalmaktadır. Yine MEDOS çalışmasında da ileri yaşlılarda ve kadın cinsiyette osteoporotik kalça kırığı riskinde artış görüldüğü bildirilmiştir (17).

Çalışmamızın sonuçlarını sosyodemografik özellikler açısından incelediğimizde eğitim durumu, medeni durum ve mesleğin OP hastasında KMY'nu etkilemediği gösterildi. Oysa bir çalışmada hastaların eğitim düzeyi yükseldikçe lomber ve femur KMY'larının arttığı bildirilmiştir (18). Yüksek eğitim seviyesine sahip olmak sağlıklı beslenme ile kalsiyumdan zengin diyet alımlarının fazla olması, iyi sağlık bilgisiyle VKi'lerinin normal sınırlarda olmasıyla sağlanıyor olabilir. Yine çalışmamızda mesleğin KMY'nu etkilememesini ayrıntılı sorgulama yapmamızdan kaynaklandığını düşünmekteyiz. Çünkü mesleki sorgulamada OP ve KMY için mesleğe özel bazı fiziksel ve kimyasal riskler tanımlanmalıydı. Şöyle ki hastanın yaşam boyu çalıştığı işler hafif işler mi yoksa ağır işler mi? işyerinde yeterince havlandırma, aydınlatma var mı? gibi soruların cevabını verecek şekilde ayrıntılı sorgulama yapmak gerekmektedir.
Menapoz ile ortaya çıkan gonadal yetersizliğe bağlı gelişen östrojen eksikliği kadınlardaki hızlı kemik kaybından sorumludur (7). Çalışmamızda erken menapozun femur bölgesinde düşük KMY ile ilişkili olduğu gösterildi. Bu sonucun östrojen eksikliğine en hassas bölgenin kalça kemiği olmasından kaynaklandığını düşünmekteyiz. Öte yandan diğer jinekolojik profil özelliklerinden menarş yaşı, menstürasyonların düzeni, doğum sayısı, doğum kontrol hapı kullanımının sorgulanmaması çalışmamızın zayıf yönünü oluşturmaktadır.

Sigara içenlerde daha düşük kemik kitlesi ve daha hızlı kemik kaybı olmaktadır (7). Sigara kullananların kilosu daha düşüktür, daha erken menapoza girmektedirler (7). Sigara içimi kan kortizol seviyelerini de yükselterek kemik mineral yoğunluğunda azalmaya neden olmaktadır (19). Yapılan çalışmalarda sigara içilmesi ile kalça KMY ve femur boynu kırık riski arasında ilişki olduğu bildirilmiştir $(19,20)$. Bundan farklı olarak çalışmamızda sigara kullanımının lomber bölgedeki düşük KMY için risk faktörü olduğu gösterildi.

Kemiğin yeniden yapılanmasında etkili mekanik faktörler kas kontraksiyonu ve yer çekimidir. Postmenapozal kadınlarda erken dönemde dirençli egzersizler östrojene bağlı vertebrada oluşacak kemik kaybında koruyucu etkiye sahiptir (7). Düzenli egzersiz yapan kişilerde OP daha az oranda görülmektedir (21). Fiziksel aktivite OP'un hem önlenmesinde, hem de tedavisinde önerilen bir yöntemdir. Tüzün ve ark.nın yaptıkları bir çalışmada, yoga osteoporotik hastalarda klasik fizik egzersize alternatif bir metod olarak kullanılmış ve OP rehabilitasyonunda etkili olduğu bulunmuştur (22). Angın ve ark.larının yaptıkları çalışmada da $O P^{\prime} l u$ yaşı hastalarda grup egzersizlerinin KMY üzerinde olumlu etkileri olduğu gösterilmiştir (23). MEDOS çalışmasında da düşük fizik aktivite risk faktörleri arasında bulunmuştur (17). Çalışmamızda da fiziksel aktivite düzeyi az olan OP hastalarında KMY'nun daha düşük olduğu gözlendi. Bunu aksine FRACTURK çalışmasında düşük fiziksel aktivitenin kalça kırığı riskine ait yeterli epidemiyolojik olmadığı ifade edilmiştir (16).

Kadınlarda vücut ağırlığı hem iskelet üzerine mekanik yük bindirerek hem de yağ dokuda depolanan östrojenler yoluyla KMY'nu arttırmaktadır $(7,24)$. Yine VKi'i fazla kadınlarda kalsiyum absorbsiyonunun daha fazla olması PTH için daha az duyarlıık oluşturmakta ve böylece kemik kitlesi korunmaktadır. Ersoy ve ark.larının çalışmasında dializ hastalarında VKi'nin azalması ile osteopeni ve OP görülmesinin arttığı gösterilmiştir (5). Çalışmamızda da VKi'nin düşük olmasının düşük KMY için risk oluşturduğu gösterildi.

Kemik mineral yoğunluğunda \%80 oranında kalıtım gibi değiştirilemez faktörlerin, \%20 oranında da diyet, güneşışı̆̆ına maruz kalma gibi çevresel faktörlerin etkili olduğu belirtilmektedir $(11,23)$. Diyetle düzenli kalsiyum alımı OP'un önlenmesinde etkilidir (25). Bizim de çalışmamızda diyette yetersiz kalsiyum alımının hem lomber hem de düşük femur KMY değerleriyle ilişkili olduğu bulunmuştur. Hastalara şimdiki diyet içerikleri değil eskiden beri olan diyet özellikleri sorgulanmıştır. Çünkü birçok çalışmada büyüme sırasında alınan kalsiyum ile KMY ve kemik kitlesi doğrudan ilişkili bulunmuştur (7). Yapılan bir 
çalışmada, kalsiyum alımının OP geliştikten sonra etkilerinin yeterli olmadığı, OP'un erken döneminde kalsiyum yetersizliği olan hastaların belirlenerek diyetle yeterli kalsiyum tüketiminin sağlanmasının, kemik kaybını azalttığı, kalsiyum düzeyi ile kemik yoğunluğu arasında pozitif yönde ilişki olduğu bildirilmiştir (26, 27). Yine MEDOS çalışmasında diyette kalsiyum eksikliği risk faktörleri arasında bulunmuştur (17).

Ailede osteoporotik kırık hikayesinin olması Kanada risk faktörleri değerlendirmesinde majör risk faktörleri arasında yer almaktadır (6). Çalışmamızda ise ailede osteoporotik kırık hikayesi olmasının OP hastasında KMY'nu etkilemediği gösterildi. Epidemiyolojik çalışmalar değişik fragilite kırığı olan kişilerde bir başka kırık olma riskinin arttığını göstermektedir (7). Bu durum KMY azalmasıyla direk ilişkilidir. Bizim çalışmamızda da fragilite kırı̆̆ı olan hastaların KMY değerlerinin fragilite kırığı olmayan hastalardan daha düşük olduğu gözlendi. Özellikle osteoporotik kırıklarda risk faktörleri arasında düşme çok önemli bir risk faktörüdür (7). Çalışmamızda düşmeye yatkınlığı olan ve olmayan OP hastalarının KMY değerleri arasında istatistiksel faklılık olmadığı gözlendi. Bu da hastaların düşünce kırık riskinin artmasında mekanik yüklenmenin daha önemli olduğunu göstermektedir.

Kemik mineral yoğunluğu kırık riskini en doğru öngörebilen yöntemdir (28). Çalışmamızda VKK olan hastalarda KMY değerlerinin düşük olduğu görüldü. MEDOS çalışmasında da düşük KMY risk faktörleri arasında sayılmaktadır (17). Ama kemik mineral yoğunluğu değerlerinin kırık açısından tek risk faktörü olmadığı da unutulmamalıdır. Kemik kütlesi kadar kemiğin gücü, travma ve kemiğin kırılganlığı da kırık oluşmasında önemli etkenlerdir (30).

Literatürde kronik hastalıklar ve ilaç kullanımlarının araştırıldığı çalışmalarda, OP'lu hastaların ortalama \%90'ında bir kronik hastalık olduğu, üçte birinde de OP'a neden olabilecek bir ilaç kullanımı olduğu gösterilmiştir $(30,31)$. Umay ve ark.ları çalışmasında OP'a eşlik eden kronik hastalık ve ek ilaç kullanımının femur boynu T skorlarına etkili olduğunu bulmuşlardı (32). Bundan farklı olarak çalışmamızda kronik hastalık sayısının KMY'nu etkilemediğini ortaya koyduk. Yine çalışmamızda OP için risk faktörü oluşturan steroid, siklosporin, diüretik, antikoagülan, antikonvülzan ilaçlarını kullanan hastalarda KMY değerleri, bu ilaçları kullanmayan hastalardan daha düşük bulunmuştur.

Sonuç olarak ileri yaş, erken menapoz hikayesi, sigara kullanımı, düşük fiziksel aktivite düzeyi, VKi'nin düşük olması, diyetle yetersiz kalsiyum alımı, vertebral kompresyon kırı̆ı ve düşme eğiliminin olmasının KMY değerlerinin düşük olmasıyla ilişkili olduğu gösterildi. Günümüze kadar ki literatür bilgilerinden farklı olarak postmenapozal osteoporotik kadınlarda eğitim düzeyi, meslek, medeni durum, ailede osteoporotik kırık hikayesi olmasının KMY'nu etkilemediği, sigara kullanımının lomber bölgedeki düşük KMY için risk faktörü olduğu, düşmeye eğilimi olan ve olmayan hastalar arasında KMY farklıı̆ı olmadığı, kronik hastalık sayısının KMY'nu etkilemediği gösterilmiştir. Çalışmamızın bazı yönleri nedeniyle sonuçları yorumlamanın dikkatli yapılması gerekmektedir. Öncelikle, bu çalışma prospektif olarak yapılmıştır ve neden-sonuç ilişkisini daha sağlam ortaya koyabilecek takip çalışması değildir. İkinci olarak, çalışmaya alınan olgu sayısı azdır. OP risk faktörlerinin KMY ile ilişkisinin değerlendirilmesi için daha çok sayıda olgunun katıldığı, randomize-kontrollü çalışmalara intiyaç bulunmaktadır. Osteoporoz konusu ile ilgilenen tüm hekimler tedavi edici stratejilerden önce önleyici yaklaşımları uygularken bu faktörleri göz önünde bulundurmalıdır. Bu şekilde kırıkların yol açacağı mortalite ve morbiditelerin engellenebileceği ve tedavi maliyetlerinin azaltılabileceği düşünülebilmektedir.

\section{Kaynaklar}

1. Kanis JA on behalf of the World Health Organization Scientific Group (2008) Assessment of osteoporosis at the primary healthcare level. Technical Report. WHO Collaborating Centre, University of Sheffield, UK. http://www.shef.ac.uk/FRAX. Accessed 15 December 2010.

2. Lewiecki EM. Bone: Using FRAX wisely: lessons from Switzerland and beyond. Nat Rev Endocrinol 2010;6:126-8.

3. Aslan A, Karakoyun O, Güler E, Aydin S, Gök MV, Akkurt S. Kastamonu'da yaşayan Türk kadınlarında kemik mineral yoğunluğu, osteoporoz yaygınlığı ve bölgesel risk faktörlerinin değerlendirilmesi: KASTÜRKOS çalışması. Eklem Hastalık Cerrahisi 2012;23:62-7.

4. Pirimoğlu MZ, Alper AGÖ, Büyükbayrak EE, Kars B, Afşin $Y$, Ünal $O$ et al. Body mass index seems the most effective factor on bone mineral density comparing postmenopausal time, age or reproductive factors in healthy postmenopausal women. Turkiye Klinikleri J Gynecol Obst 2011;21:1-5.

5. Ersoy FF, Passadakis SP, Tam P, Memmos ED, Katopodis PK, Ozener $C$, et al. Bone mineral density and its correlation with clinical and laboratory factors in chronic peritoneal dialysis patients. J Bone Miner Metab 2006;24:79-86.

6. Brown JP, Fortier M, Frame H, Lalonde A, Papaioannou A, Senikas $\checkmark$, et al. Osteoporosis guidelines committee. Canadian consensus conference on osteoporosis, 2006 update. J Obstet Gynaecol Can 2006;28:95-112.

7. Sarıdoğan ME. Osteoporozda risk faktörlerinin değerlendirilmesi. In: Sarıdoğan ME, Gökçe-Kutsal Y, editörler. Osteoporoz tanı ve tedavi kılavuzu. İstanbul, 2005. s. 15-25.

8. James WP, François PJ. The choice of cut-off point for distinguishing normal body weights from underweight or 'chronic energy deficiency' in adults. Eur J Clin Nutr 1994;48:179-84.

9. Orimo H, Shiraki M, Hayashi Y, Hoshino T, Onaya T, Miyazaki S, et al. Effects of $1 \alpha$ hydroxyvitamin D3 on lumbar bone mineral density and vertebral fractures in patients with postmenopausal osteoporosis. Calcif Tissue Int 1994;54:370-6.

10. Kelly TL, Von Stetton E. Performance evaluation of a multidetector DXA device. J Bone Miner Res 1991;6:168.

11. Raisz LG. Pathogenesis of osteoporosis: concepts, conflicts, and prospects. J Clin Invest 2005;115:3318-25.

12. Dilşen G, Göksoy T, Barden HS, Selim N, İşsever H. Sağlıklı türk toplumunda kemik mineral yoğunluğu değerleri. Aktüel Tıp Dergisi 2001;6:96-108.

13. Kozacı DL, Şavk Ö, Özkan I, Çullu E, Alparslan B, Yürekli Y et al. Evaluation of osteoporosis in early and late postmenopausal women: correlations betwe-en bone mineral density and bone turnover markers. Eklem Hastalık Cerrahisi 2006;17:28-32.

14. Ersöz M, Kahramanlar F. Proksimal femur total kemik mineral yoğunluğu değerlerine göre normal ya da osteopenik bulunan postmenopozal kadınlarda femur proksimalı bölgesel ölçümlerine göre osteoporoz ve osteopeni sıklığı. Türk Osteoporoz Dergisi 2002;8:141-6.

15. Tüzün \$̧, Karacan I, Selim N, Tüzün F. Bone mineral density in a Normal Turkish female population. Turk J Phys Med Rehab 2004;50:10-6.

16. Tuzun S, Eskiyurt N, Akarirmak U, Saridogan M, Senocak M, Johanson $\mathrm{H}$ et al. Incidence of hip fracture and prevalence of osteoporosis in Turkey: the FRACTURK study. Osteoporos Int 2012;23:949-55. 
17. Dequeker J, Tobing L, Rutten V, Geusens P. Relative risk factors for osteoporotic fracture: a pilot study of the MEDOS questionnaire. Clin Rheumatol 1991;10:49-53.

18. Nakamura K, Takahashi S, Oyama M, Nashimoto M, Saito $T$ Tsuchiya $Y$, et al. Incidence and risk factors associated with hip fracture in institutionalised elderly people in Japan. Age Ageing 2009;38:478-82.

19. Nakamura K, Takahashi $S$, Oyama M, Nashimoto $M$, Saito $T$, Tsuchiya $Y$, et al. Kırk beş yaş üstü kadınlarda osteoporoz risk faktörleri. Dicle Tip Derg 2009:36:258-66.

20. Hollenbach KA, Barrett-Connor E, Edelstein SL, Holbrook T. Cigarette smoking and bone mineral density in older men and women. Am J Public Health 1993;83:1265-70.

21. Vondracek SF, Linnebur SA. Diagnosis and management of osteoporosis in the older senior. Clin Interv Aging 2009;4:121-36.

22. Tüzün $S$, Aktas I, Akarirmak $U$, Sipahi $S$, Tüzün $F$. Yoga might be an alternative training for the quality of life and balance in postmenopausal osteoporosis. Eur J Phys Rehabil Med 2010;46:69-72.

23. Angin $E$, Erden $Z$. The effect of group exercise on postmenopausal osteoporosis and osteopenia. Acta Orthop Traumatol Turc 2009;43:343-50.

24. Berecki-Gisolf J, Spallek M, Hockey R, Dobson A. Height loss in elderly women is preceded by osteoporosis and is associated with digestive problems and urinary incontinence. Osteoporos Int 2010;21:479-85.
25. Guzel R, Kozanoglu E, Guler-Uysal F, Soyupak S, Sarpel T. Vitamin $D$ status and bone mineral density of veiled and unveiled Turkish women. J Womens Health Gend Based Med 2001;10:765-70.

26. Turhanoğlu AD, Güler H, Özer C. Yaşı kadınlarda osteoporoz tedavisinin yaşam kalitesine etkisi. Osteoporoz Dünyasından 2008;14:7-11.

27. Lips P, van Schoor NM. Quality of life in patients with osteoporosis. Osteoporos Int 2005; 16:447-55.

28. Tüzün Ş, Akırmak Ü, Dinç A. Osteoporozun tanımı ve sınıflandırılması. Kemik ve eklem dekadında osteoporoz. Aventis Pharma Türkiye, İstanbul, 2002. s. 9-13.

29. Gür S. Kemik kalitesi ve kırık ilişkisi. In: Gökçe-Kutsal Y, editör. Osteoporozda kemik kalitesi. Güneş Kitabevi, Ankara, 2004. p. 235-54.

30. Assantachai P, Angkamat W, Pongpim P, Weattayasuthum C, Komoltri C. Risk factors of osteoporosis in institutionalized older Thai people. Osteoporos Int 2006;17:1096-102.

31. Chen YT, Miller PD, Barrett-Connor E, Weiss TW, Sajjan SG, Siris ES. An approach for identifying postmenopausal women age 50-64 years at increased short-term risk for osteoporotic fracture. Osteoporos Int 2007;18:1287-96.

32. Umay E, Tamkan U, Gündoğdu I, Umay S, Çakcı A. Osteoporoz risk faktörlerinin kemik mineral yoğunluğuna etkisi. Türk Osteoporoz Dergisi 2011;17:44-50. 